\title{
Performance of Composite Paste Barricades at Goldcorp Inc., Red Lake Mine, Ontario, Canada
}

\author{
P.B. Hughes Department of Mining Engineering, University of British Columbia, Canada \\ R. Pakalnis Department of Mining Engineering, University of British Columbia, Canada \\ M. Hitch Department of Mining Engineering, University of British Columbia, Canada \\ G. Corey Goldcorp Inc., Canada
}

\begin{abstract}
Appropriate strength barricades and fill fences are a necessary component of underhand cut and fill mining operations and stoping operation in general. These important structures are subject to a number of stresses and strains as a result of the deposition, and curing of the backfill material. Parametric monitoring of fill fences gives the engineer the required data to predict not only the behaviour of the paste backfill as it is being deposited but also the ability to predict the deformation and eventual failure of the barricade. A study was undertaken to determine the performance of the paste barricades at Goldcorp Inc. 's Red Lake Mine using real time instrumentation to monitor the stresses, strains and deformation of paste and paste barricades during placement. The barricades at the mine are a standardised barricade comprised of $10 \mathrm{~cm}$ of shotcrete applied to a rebar skeleton spaced nominally $60 \mathrm{~cm}$ apart. In total eight fill barricades were instrumented to determine the behaviour of the paste during the loading. Complementing the eight barricade tests, an instrumented destructive test was carried out to determine the ultimate capacity of the composite barricade. It was determined that the paste backfill behaves as a Rankine-like soil in the initial stages of placement with an average coefficient of lateral earth pressure, Ka, of 0.56. The destructive test determined that the yielding stress of a paste barricade is approximately $100 \mathrm{kPa}$. The results of the investigation have resulted in operational changes in the placement of paste at the mine.
\end{abstract}

\section{Introduction}

Researchers at the Norman B. Keevil Institute of Mining Engineering at the University of British Columbia have recently completed a study on the performance of fill barricades at Goldcorp Inc.'s Red Lake Mine. Eight fill barricades were monitored for stress and strain response during production pours and one fence was tested under a direct load until failure. Once the applied stresses due to the paste were known, suitable parameters can be assigned to the paste during initial placement. Further to the properties of the paste, the response of the barricades to the applied load was analysed to determine the ultimate loading on to the fence. In coupling these findings, a more beneficial paste backfill program can be designed for the mine.

Red Lake Mine interest in this research was due to the safety and operational benefits, thusly the economic impacts of the results of this study are significant. The economic benefits are the understanding of the interaction between paste and paste barricades and fence capacities can increase production due to placement increases. The increase in production can be realised by increasing fill pour rate, ultimately leading to continuous paste pours, which would allow more rapid backfill times for stope completion. A potential safety benefit is that by increasing the fill rate, discontinuities ('cold joints') between successive paste pours would be minimised; these discontinuities create groundfall hazards in underhand cut and fill stopes.

\section{Site introduction}

The Red Lake Mine extracts ore from a world-class gold deposit located in Balmertown, western Ontario, Canada. With Goldcorp's defining of the High Grade Zone at depth in 1994 (Twomey and McGibbon, 2001), Red Lake Mine had to develop novel methods to mine the ore in a cost-efficient manner. Through the implementation of mechanised overhand cut-and-fill, underhand cut-and-fill and pillar extraction, the mine has become a leader in high-grade, low tonnage mining. With the selection of the mining method, paste 
backfill technology was employed at the mine to provide a safe engineered backfill that can be used to provide global stability in mine sequencing that miners work in close proximity.

\subsection{Mining method}

Red Lake currently utilises two mining methods: primarily mechanised cut and fill $(60 \%$ overhand, $25 \%$ underhand of overall production) and occasional long hole stoping in terms of sill extraction (15\% of overall production). MCF commenced below the 31 level at Red Lake Mine (1400 m depth) due in part to both high-grade gold and the high stresses developed through mining. Long hole stoping is typically used in low grade areas or in high stresses as a destress slot allowing the removal of ore in a low stress environment through underhand cut and fill method.

Once the stopes are mined out fill barricades are constructed to contain the paste poured within the stopes. At Red Lake Mine, fill barricades consist of an anchored \#6 rebar skeleton placed on $0.6 \mathrm{~m}$ centres and covered with a minimum of $10 \mathrm{~cm}$ of shotcrete (Figures $1 \mathrm{a}$ and $1 \mathrm{~b}$ ).

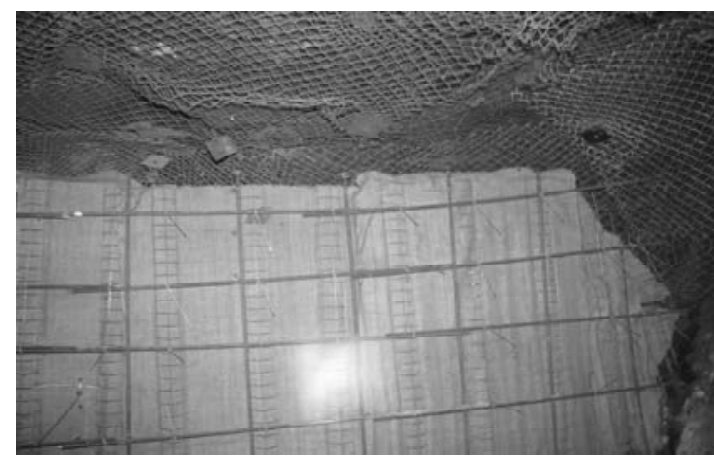

a)

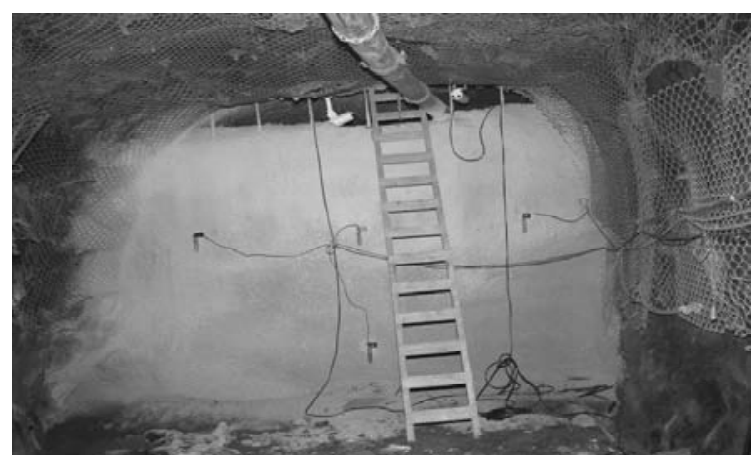

b)

Figure 1 a) Barricade rebar skeleton; b) Completed instrumented barricade

\subsection{Paste practices}

Red Lake Mine incorporated paste backfill technology developed by Golder Associates Ltd (2000) Paste Technology Inc. into their mining practice in 2000.

The paste is mixed on surface and pumped underground through a gravity fed system. The batch plant can produce 80 tonnes per hour of paste with average unit weight of two tonnes $/ \mathrm{m}^{3}$, the average pouring rate at the stope is $40 \mathrm{~m}^{3} / \mathrm{hr}$ (Mah et al., 2003).

The paste recipe at Red Lake is between 5-10\% Portland cement by dry weight (Mah et al., 2003). Typically, the higher cement contents are used for underhand cut and fill sill mats and mucking floors, as it is less susceptible to wear. The lower cement content is used in the overhand cut and fill stopes as the strength of the paste is not crucial for ground support. Red Lake Mine defines the percentage of cement for the paste as follows:

$$
\text { cement } \%=1 \text { - [dry weight of tailings / (weight of dry cement + weight of dry tailings)] }
$$

The mineralogical composition of the fines is primarily quartz and dolomite minerals with minor amounts of chlorite, mica, amphibolites and feldspar; the grain size ranges between 3 and 100 microns. The paste slump averages $24.1 \mathrm{~cm}$ with an unconfined compressive strength (UCS) of 2MPa. This strength value is from paste tested at surface; through observations of cured paste in stopes during this study, there appears to be a discrepancy between the surface tests and the cured paste in stopes with higher values observed underground.

Pouring rates are limited to $0.3 \mathrm{~m} / \mathrm{hr}$ in height, no pour is to exceed a maximum height of $1.5 \mathrm{~m}$, and when placing successive lifts allow $24 \mathrm{hr}$ set time before placement of the second lift are mandated. It can be seen that by understanding the loading mechanics of paste pours will allow for an increase in production by maximising the fill rates and pour heights for the designed barricades. 


\section{$3 \quad$ Barricade monitoring program}

Nine paste barricades were instrumented to determine the stresses and strains on the fence during loading. Eight of the fences were instrumented to record stress and strains during production paste pours, the other fence was instrumented to record the stress and strains during a controlled destructive fill fence test. The destructive test was required to understand the failure mechanics of the fence and to provide interpretation of production pour test results with respect to fence capacity. Table 1 summarises the instrumented paste barricades.

The instrumentation used for the monitoring was a selection of vibrating wire instruments that were logged during the placement of the paste. The instruments used in the fence were earth pressure cells (EPC), load cells, shotcrete embedded strain gauges, rebar strain gauges and tilt metres.

Table 1 Fill fence inventory

\begin{tabular}{lllll}
\hline & \multicolumn{5}{c}{ Instruments } \\
\hline \multirow{2}{*}{ Fill Fence } & $\begin{array}{l}\text { Earth } \\
\text { Pressure } \\
\text { Cells }\end{array}$ & $\begin{array}{l}\text { Shotcrete } \\
\text { Strain } \\
\text { Gauges }\end{array}$ & $\begin{array}{l}\text { Rebar } \\
\text { Strain } \\
\text { Gauges }\end{array}$ & $\begin{array}{l}\text { Measured } \\
\text { Fill Height }\end{array}$ \\
\hline $32-826-8$ & 5 & 0 & 0 & No \\
$37-746-2$ & 1 & 1 & 0 & No \\
$34-806-4$ & 2 & 2 & 0 & No \\
$31-806-3$ & 1 & 1 & 0 & Estimated \\
$36-746-1$ & 2 & 2 & 0 & Estimated \\
$34-806-1$ & 1 & 1 & 0 & Estimated \\
$34-786-14 a$ & 2 & 3 & 3 & Yes \\
$34-786-14 b$ & 2 & 3 & 3 & Yes \\
Destructive test & 2 & 3 & 3 & N/A \\
\hline
\end{tabular}

Typical instrument layout for the monitored paste pours are shown in Figure 2. In general EPCs were installed $1 / 3$ and $1 / 2$ of the total height of the fence to determine the loads during the paste pour. Rebar strain and concrete strain gauges were installed horizontally and vertically in the centre of the fence as it was expected that these would be the areas of largest strain.

During the placement of paste, the instrument readings were recorded with a data logger that measured readings every 30 seconds. Fill heights were estimated by marking up the wall on the paste side and periodically recording the height during placement through either visual checks or infrared recordings.

The destructive fill fence test was necessary as the ultimate strength of the fence was unknown. The destructive barricade test consisted of a $1 \mathrm{~m} \mathrm{x} 1 \mathrm{~m}$ loading plate secured in the middle of the fence prior to shotcrete application. Loads were applied by a hydraulic ram attached to an I-beam located $60 \mathrm{~cm}$ in front of the fence. Instruments were installed in the fence as shown in Figures 3. Further to the instrumentation shown, a load cell was installed adjacent to the hydraulic ram, as seen in Figure 4. 


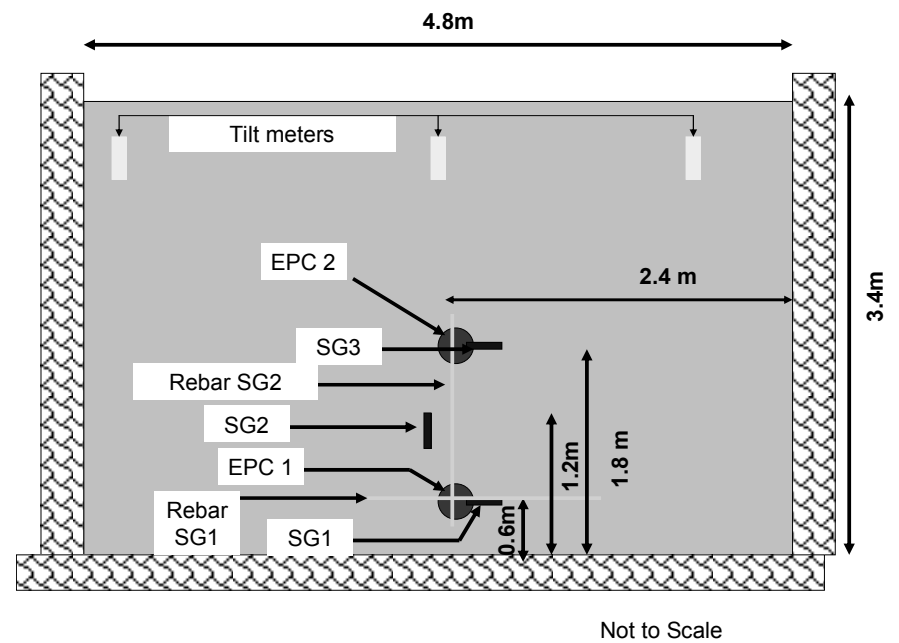

Figure 2 Typical instrumentation layout

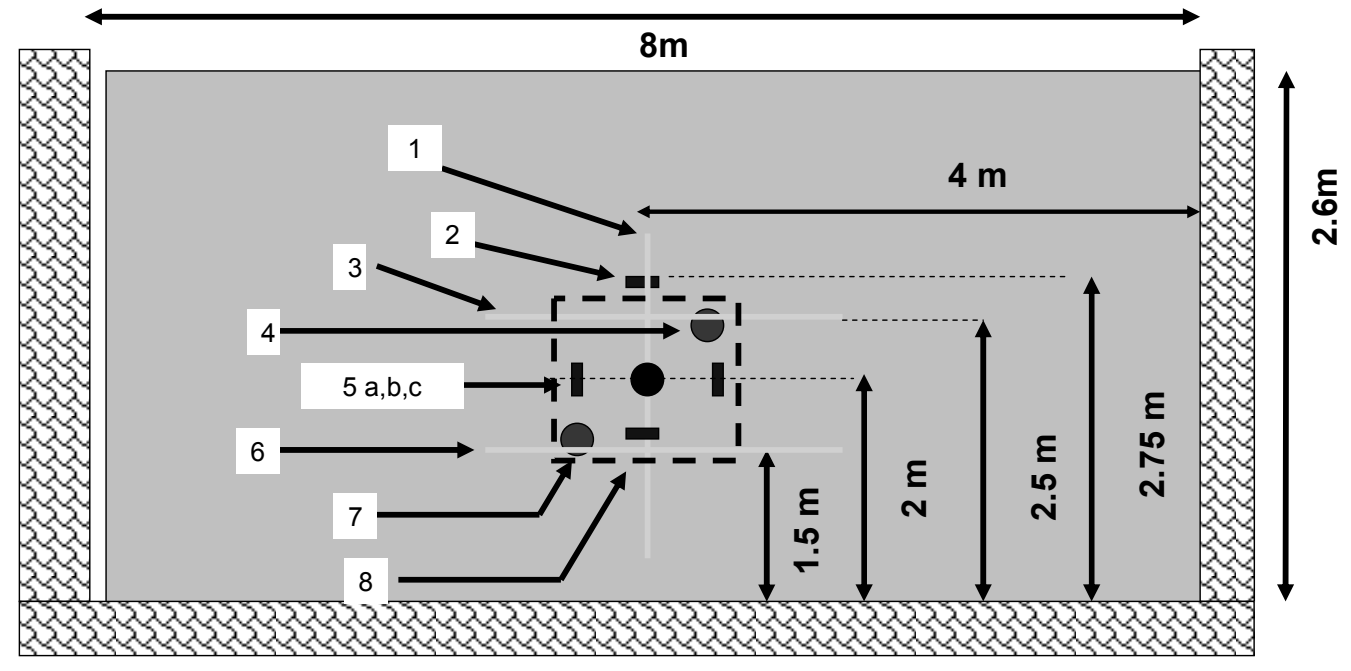

1 Vert. Rebar SG

5 (a) Vert Left SG (b) Load Cell (c) Vert Right SG

2 Horiz. Top SG

3 Horiz. Top Rebar SG

4 EPC Top Left

6 Horiz. Bottom Rebar SG

7 EPC Bottom Right

$81 \mathrm{~m} \times 1 \mathrm{~m}$ Loading Plate

Not to Scale

Figure 3 Destructive fill fence instrument layout

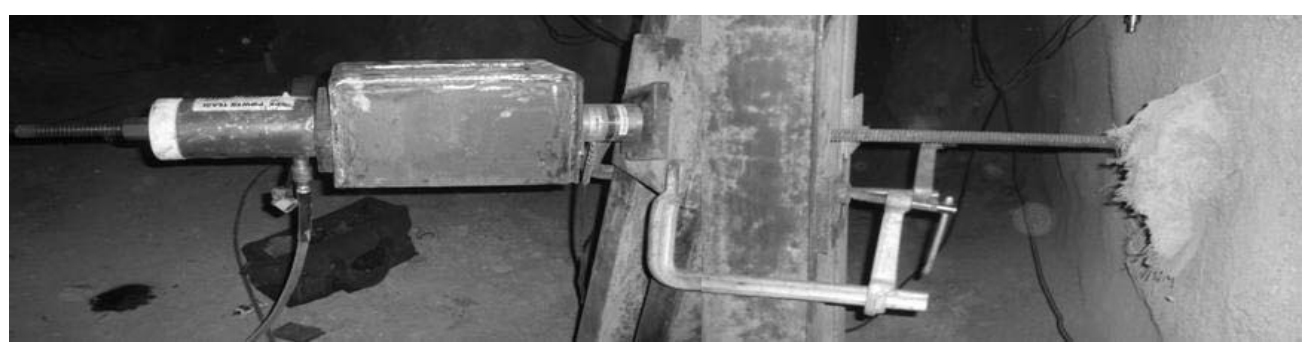

Figure 4 Photograph of instrument layout for destructive fill fence test 
For the destructive test incremental loads were applied to the fence and time and readings were taken once the hydraulic system was seated. Test loads of $0.5,1,1.5,2,3,4,5,7,9,11$ and $13 \mathrm{t}$ with respect to the hydraulic gauge were applied to the fence.

The test did not demonstrate any noticeable cracks during testing. Noticeable deformation of the fence was evident but no signs of distress were obvious. It was estimated that the fence had undergone $7 \mathrm{~cm}$ of horizontal deformation based on hydraulic jack piston displacement, however no measurement were taken to verify these estimates since no personnel were allowed in front of the fence. The fence did not fail catastrophically during the testing.

\section{$4 \quad$ Results}

Typical results for stress and strain recorded during the placement of paste are shown in Figure 5 and 7 . It can be see that the readings of the EPCs reflect the height of paste within the stope. The large spike in EPC near the 04-Aug-04 reading is due to the flushing of the water lines between paste pours (Figure 5). This large spike was noted in five of the monitored paste pours, in some cases the largest pressures experienced by the fence were during the flushing of the water lines. The strains in Figure 6 also reflect the height of paste within the stope, what is interesting is that initially a tensile strain is recorded by the instruments followed by compressive strain.

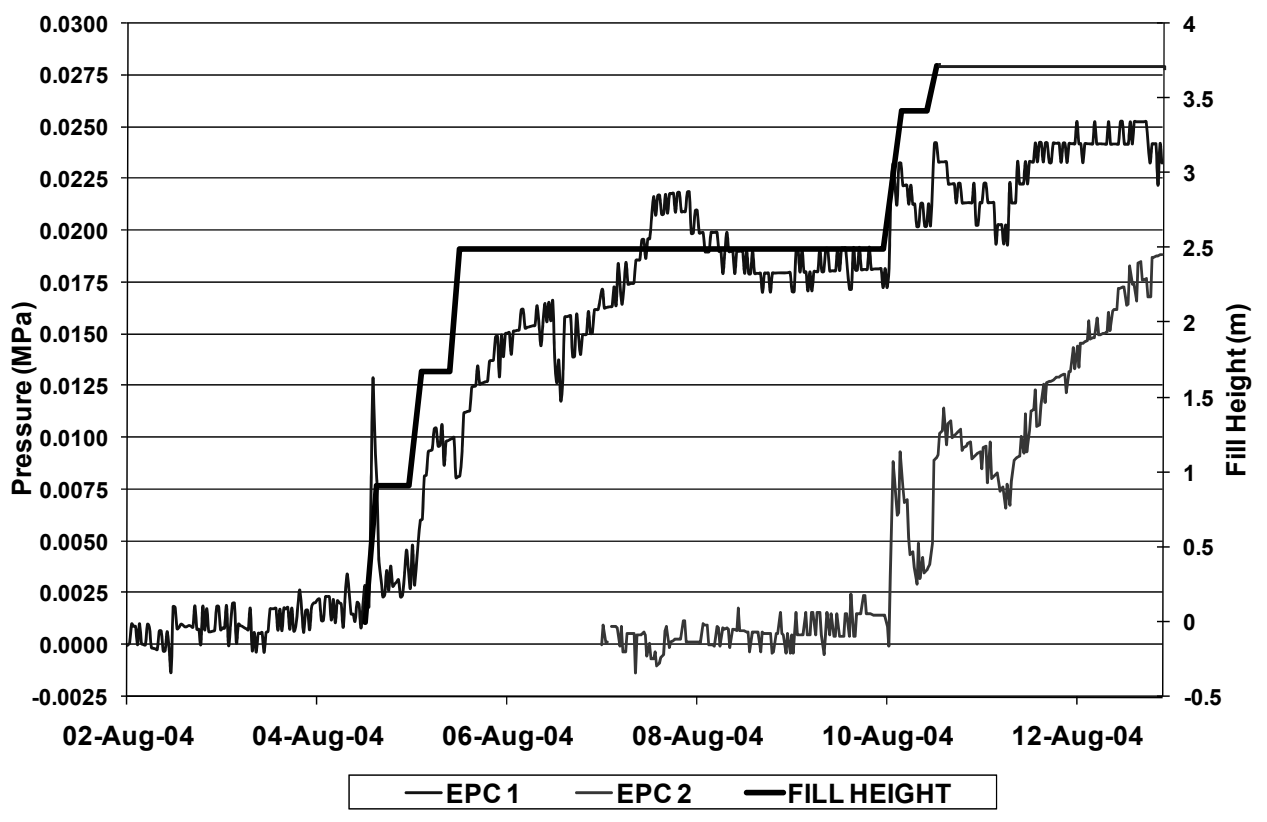

Figure 5 Typical stress measurements 


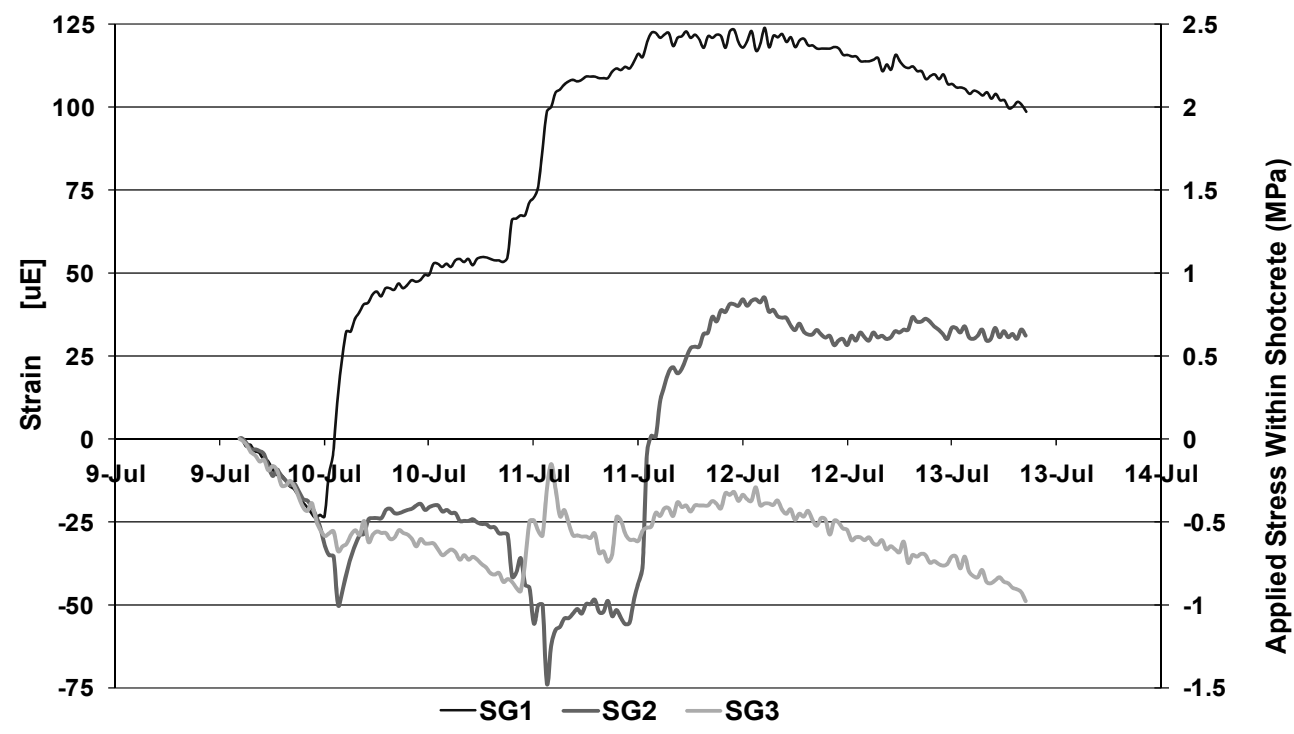

Figure 6 Typical strain measurements

Table 2 summarises the maximum pressures and strains recorded in all fences. The largest pressure recorded in the production paste pour was $50 \mathrm{kPa}$ in Fill Fence 32-826-8. Comparatively, the destructive barricade maximum recorded pressure was $127 \mathrm{kPa}$. The maximum strain recording in fill fence 34-806-4 was due to a faulty gauge which provided erroneous readings. The largest maximum strain recorded during a paste pour in the shotcrete was a tensile strain of $375 \mu \varepsilon$ and the maximum value in the rebar was $130 \mu \varepsilon$. In comparison during the destructive barricade test the maximum recorded strains in the shotcrete and rebar were $-50 \mu \varepsilon$ and $1100 \mu \varepsilon$ respectively.

Table 2 Summary of maximum stress and strains on fill fence

\begin{tabular}{llllll}
\hline Fill Fence & $\begin{array}{l}\text { Height } \\
(\mathbf{m})\end{array}$ & $\begin{array}{l}\text { Width } \\
(\mathbf{m})\end{array}$ & $\begin{array}{l}\text { Maximum } \\
\text { Pressure } \\
\mathbf{( k P a})\end{array}$ & $\begin{array}{l}\text { Maximum } \\
\text { Strain in } \\
\text { Concrete }(\boldsymbol{\mu \varepsilon})\end{array}$ & $\begin{array}{l}\text { Maximum } \\
\text { Strain in } \\
\text { Rebar }(\boldsymbol{\mu \varepsilon})\end{array}$ \\
\hline $32-826-8$ & 4.5 & N/A & 50 & N/A & N/A \\
$37-746-2$ & 3.9 & 3.6 & N/A & N/A & N/A \\
$34-806-4$ & 3.6 & 5.35 & 22.5 & 2000 & N/A \\
$31-806-3$ & 4.25 & 4.25 & 20 & 125 & N/A \\
$36-746-1$ & 5.25 & 12.3 & 25 & -220 & N/A \\
$34-806-1$ & 3.7 & 6.9 & 40 & -375 & N/A \\
$34-786-14 a$ & 3.4 & 4.8 & 14 & 35 & 25 \\
$34-786-14 b$ & 3.85 & 3.5 & 19 & 180 & 130 \\
Destructive test & 2.6 & 8 & 127 & -50 & 1100 \\
\hline
\end{tabular}

\section{$5 \quad$ Analysis}

The analysis consists of determining the loading mechanics of the paste, the performance of the fence under loading and the capacity of the fence based on the destructive barricade test. 


\subsection{Loading mechanics of paste}

The loading mechanics of paste were based on theoretical approaches based on values obtained during the field study. The relationship between the horizontal loads and the vertical loads during paste pouring was essential to understand the fill fence/paste interactions. The lateral earth pressures was analysed with Rankine Theory (Terzaghi et al., 1996). Relating of Rankine Theory to backfill design was previously proposed by Mitchell et al. (1975), Revell and Sainsbury (2007), Marcinyshyn et al. (1997) and Dehn et al. (2007).

Rankine Theory relates the horizontal pressure to the vertical pressure based on a coefficient which determines whether the soil is active, passive or at rest (Terzaghi et al., 1996). For this analysis the soil must be considered homogenous, well drained, and cohesionless and importantly has a degree of internal friction. In Rankine Theory, a soil is considered active when it is applying a force to an external structure, as is the case with paste loading a fill fence.

The Rankine Theory provides the following formula to estimate the active lateral earth pressure:

$$
\sigma_{\mathrm{h}}=\mathrm{K}_{\mathrm{a}} \sigma_{\mathrm{v}}
$$

where:

$$
\begin{gathered}
\sigma_{\mathrm{v}}=\gamma \mathrm{H} \\
\mathrm{K}_{\mathrm{a}}=(1-\sin \Phi) /(1+\sin \Phi)
\end{gathered}
$$

$\Phi=$ internal angle of friction.

$\gamma=$ unit weight of soil

$=18.63 \mathrm{kN} / \mathrm{m}^{3}$ (Dehn et al., 2007).

$\mathrm{H}=$ height of soil $(\mathrm{m})$.

An issue with the data was that four of the instrumented barricades had no measurement of height during paste pours. Fill heights were necessary to determine the vertical pressure of the paste, thus fences without fill height readings were omitted from the analysis. For the fill fences with measured heights, the corresponding lateral pressure for fill heights were compared as shown in Figure 7. The slope of the best fit line can be related to $\mathrm{Ka}$ value for the paste. The data has a linear relationship with a slope ratio of approximately 9 horizontal: 1 vertical and an r-squared value of 0.79 demonstrating a good correlation.

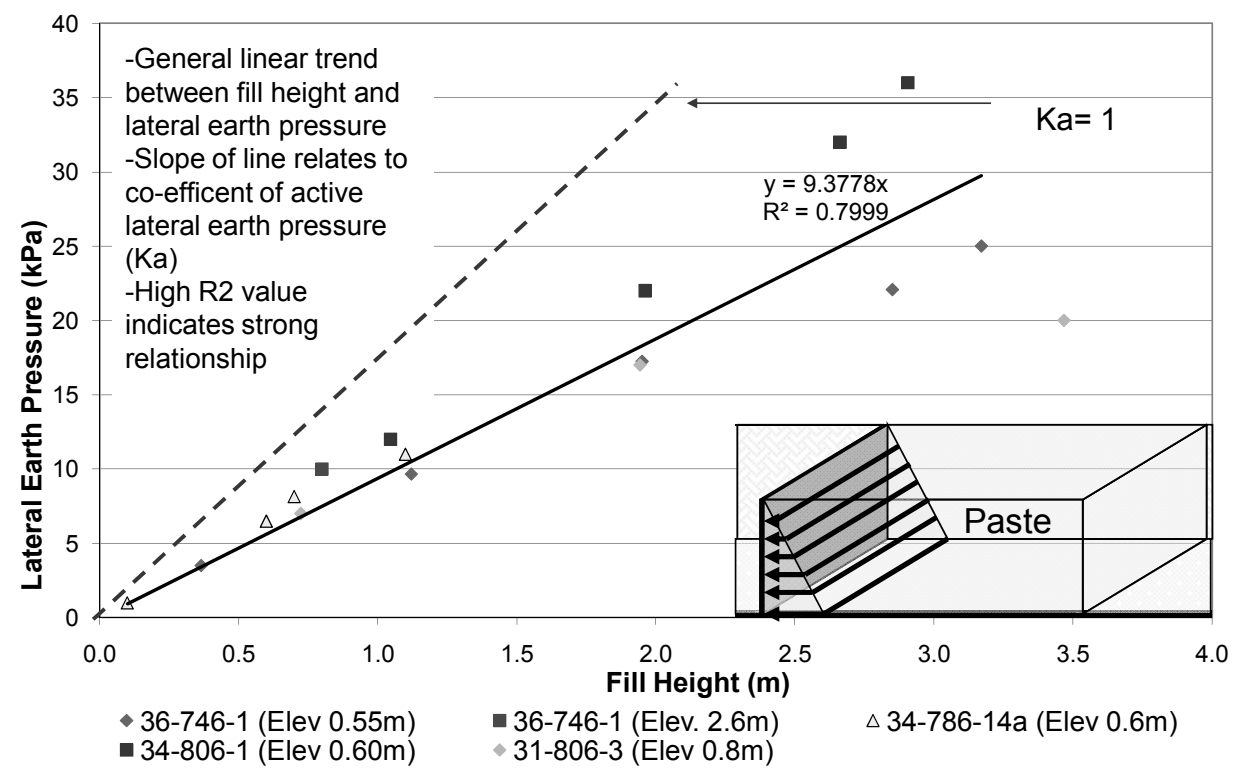

Figure 7 Lateral earth pressures versus recorded fill height 
Further to the above analysis of measured height of paste versus lateral earth pressure, one fill fence had adjacent vertical and horizontal EPC situated side by side, $0.25 \mathrm{~m}$ above the floor. This configuration of instruments was optimum as it directly related the horizontal stresses and vertical stresses. The slope of the line of the horizontal versus vertical stress in Figure 8 is the coefficient of active soil pressure value. As can be seen this has a value of 0.55 and a $\mathrm{R}^{2}$ value of 0.92 indicating a very good correlation. The deviation from the best fit line at the horizontal $0.05 \mathrm{MPa}$ point is most likely due to the curing and the development of self cohesion within the paste.

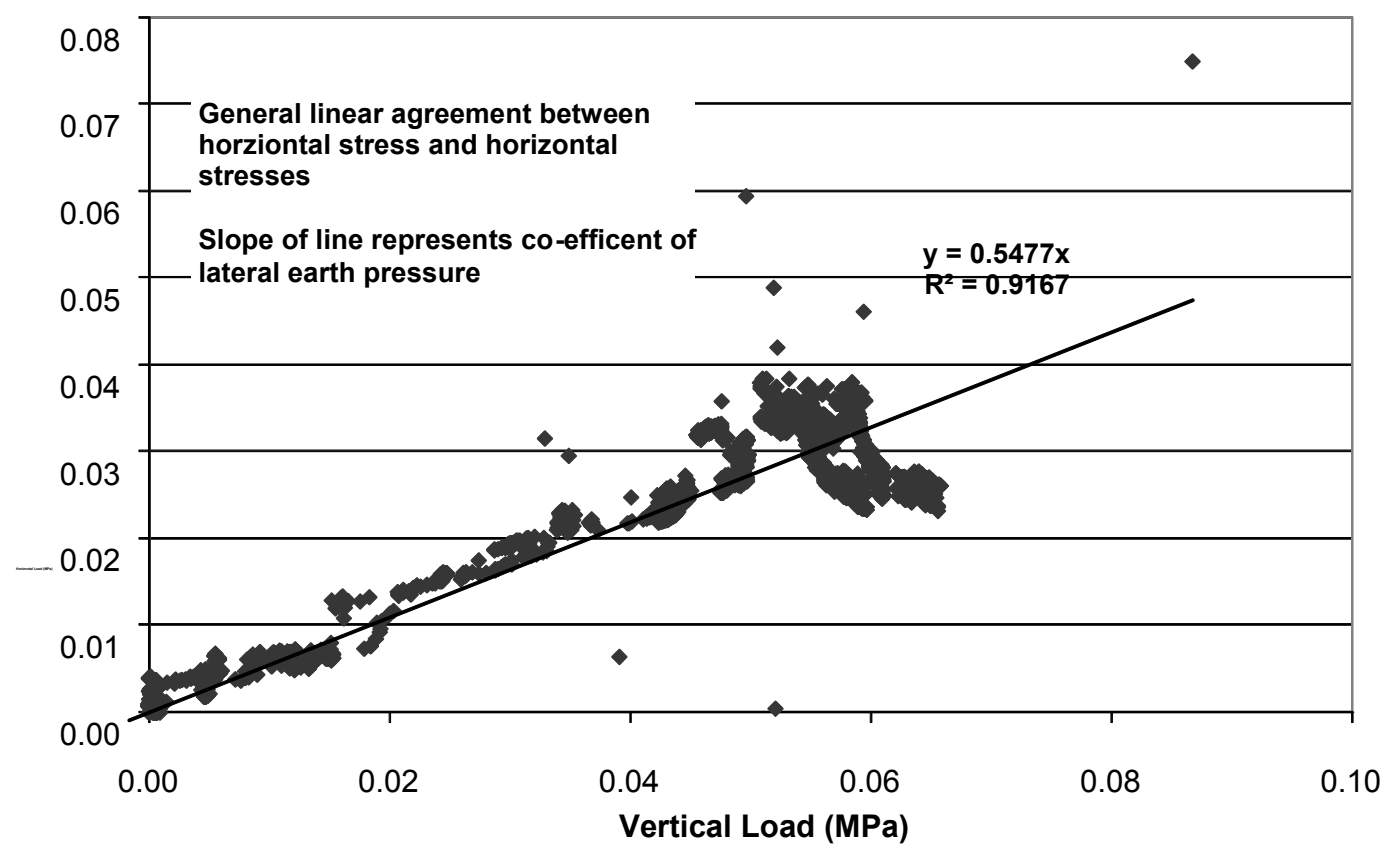

Figure 8 Fill fence 32-826-8: horizontal load versus vertical load

The comparison of horizontal pressures versus vertical pressures proved that a linear relationship existed. This leads the conclusion that paste during initial placement behaves as a Rankine soil. From the data collected co-efficient of active earth pressure $(\mathrm{Ka})$ and friction angle for the paste were calculated using Equation (2). The results are presented in Table 3.

Table 3 Summary of friction angle analysis

\begin{tabular}{llll}
\hline Fill Fence & $\begin{array}{l}\text { Instrument } \\
\text { Height }(\mathbf{m})\end{array}$ & $\begin{array}{l}\text { Ka } \\
\text { Value }\end{array}$ & $\begin{array}{l}\text { Friction } \\
\text { Angle }\end{array}$ \\
\hline $36-746-1$ & 0.55 & 0.46 & 21.9 \\
& 2.6 & 0.69 & 10.4 \\
$34-806-1$ & 0.6 & 0.63 & 13 \\
$34-786-14 \mathrm{a}$ & 0.6 & 0.57 & 15.9 \\
$34-786-14 \mathrm{~b}$ & 0.8 & 0.43 & 23.8 \\
$32-826-8$ & 0.25 & 0.55 & 16.9 \\
\hline Average & & 0.56 & 16.99 \\
\hline
\end{tabular}




\subsection{Stress versus strain response of barricades}

The stress-strain behaviour analysis of the fence was used to determine if the fence undergoes any plastic strain during imposed loads. The plastic strain is defined as the deformation of a material that is irrecoverable when the applied load is removed. When a material enters a plastic strain dominant behaviour it is said to be yielding and the stress versus strain curve begins to flatten out (Mott, 2002).

To carry out the stress versus strain analysis, an assumption has to be made that the strain in the strain gauge is directly related to the imposed load of the paste and not due to bending moments of the fence. Further, a fill rate was determined by the height of paste in the stope and by the time taken to reach the fill height. These assumptions allow the strains experienced by the fence to be directly related to the imposed pressure of the paste.

The recorded strain values are compared to the calculated imposed stress readings. It should be noted that since instruments are located above the floor of the stope, only values where the assumed fill height is above the instrument can be used. Figure 9 show a typical stress strain plot for a paste pour at Red Lake Mine. This near-linear behaviour was seen for all fences for the stage of the analysis.

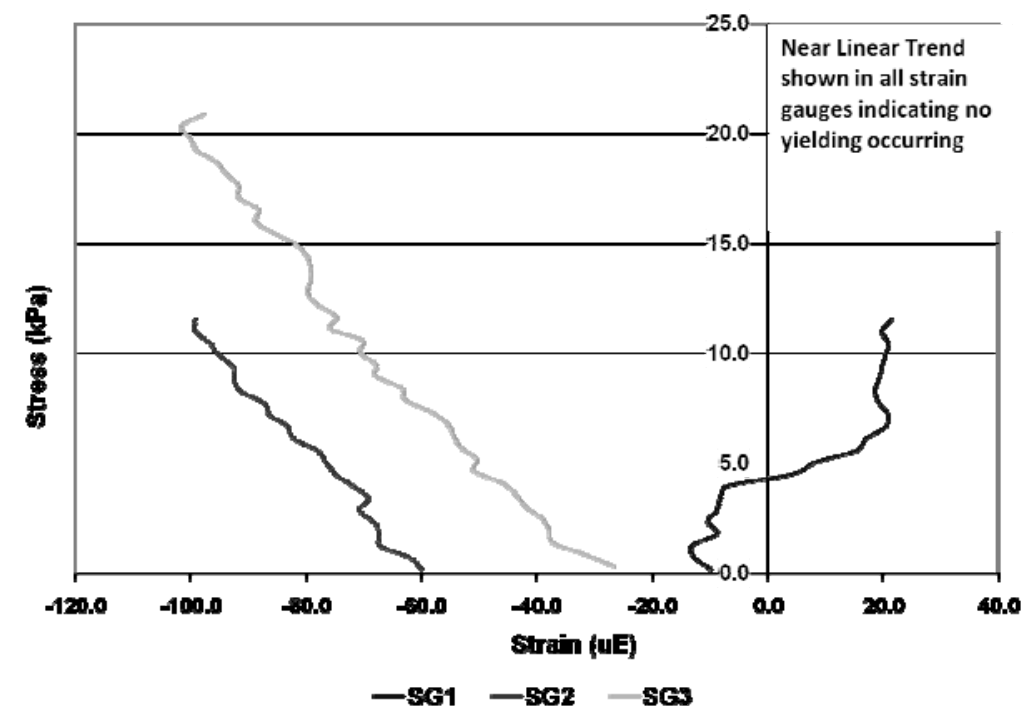

Figure 9 Fill fence 36-746-1 stress versus strain

The stress versus strain plot for the destructive fill fence is shown in Figure 10. It should be noted that for this test the strain related directly to the applied stress, as opposed to the assumed stresses in the other cases. As can be seen in Figure 10, the stress versus strain plot shows the yielding of the rebar elements around the $100 \mathrm{kPa}$ load. Above $100 \mathrm{kPa}$, slight increases in stress cause a large non-linear increase in strain. It is hypothesised that this is due to plastic deformation within the rebar. It should be noted that the concrete strain gauges are not undergoing plastic strain at these loads. It can be concluded that for the destructive fill fence test, the rebar membranes are taking the majority of the applied loads, undergoing plastic deformations. 


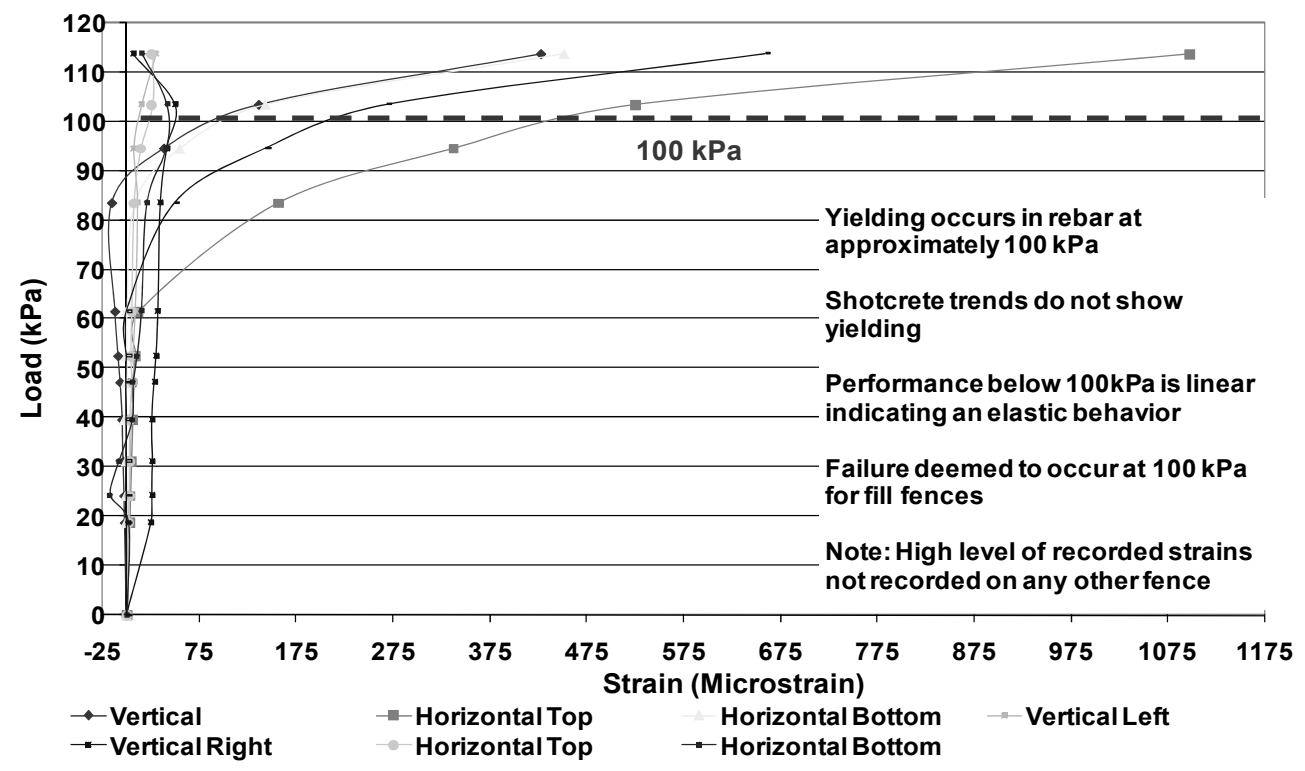

Figure 10 Destructive fill fence test stress versus strain

\subsection{Performance of fence under normal loading}

Figure 11 shows a combination plot of all the stress versus strain measurements for production paste barricade measurements and for the destructive test. It can be seen that only the rebar strain gauges in the destructive fill fence yielded during testing and that the strain gauges within the shotcrete elements failed to yield under loading. Further, the highest loads occurred in the destructive fill test, and based on this analysis, it can be concluded that below loads of approximately $100 \mathrm{kPa}$ fill fences do not exhibit yielding behaviour. With a yielding value of $100 \mathrm{kPa}$ and a determine Ka value of 0.56 , the Rankine Theory implies that the fence, as constructed, could withstand a paste height of $9.5 \mathrm{~m}$.

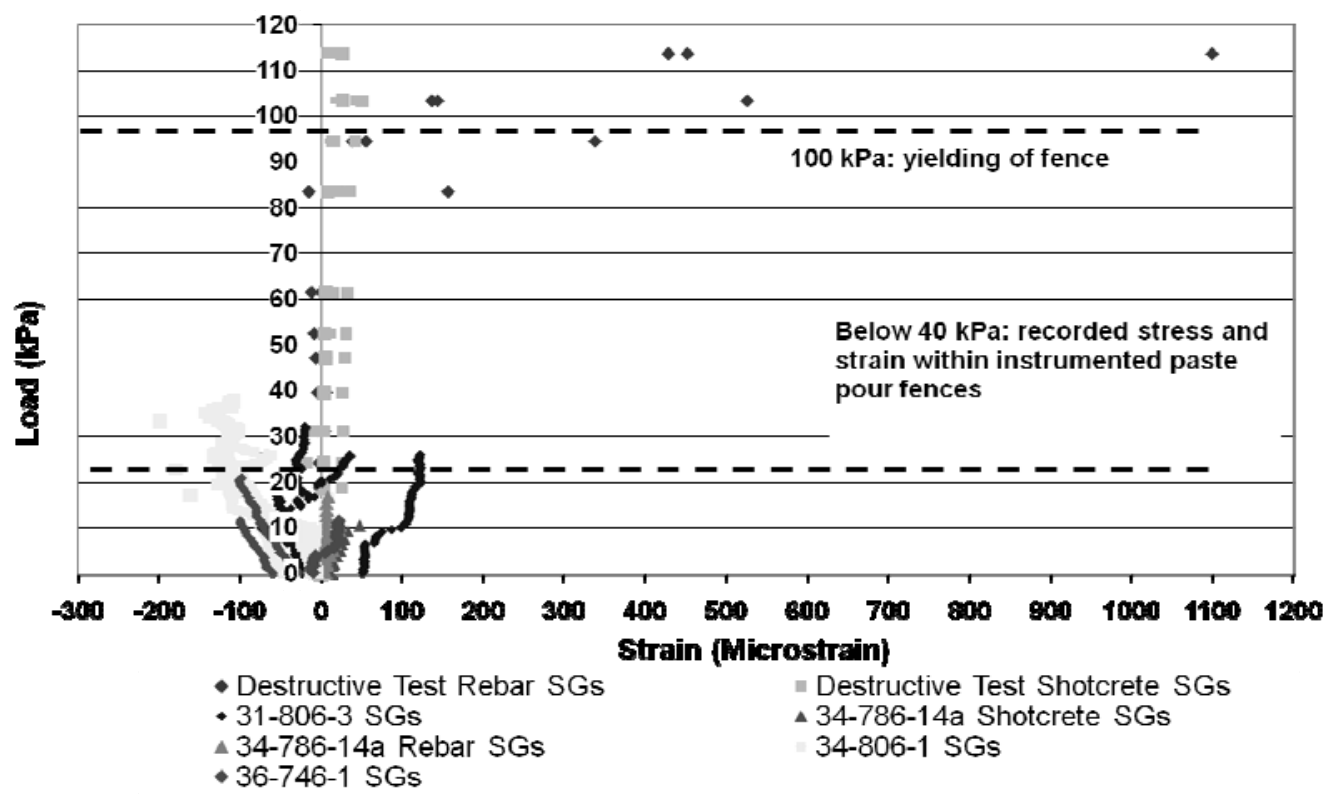

Figure 11 All fences: stress versus strain 


\section{Discussion}

From the analysis, there exists a strong relationship between the paste height and lateral earth pressure during the initial stages of paste pours. The coefficient of active lateral earth pressure, $\mathrm{K}_{\mathrm{a}}$, was determined to be 0.56 and did not seem to be affected by the percent of cement in the paste or the fill rate. This value of $K_{a}$ demonstrates that the loading of the fence at Red Lake is not hydrostatic, and that the paste has an internal friction during placement.

The capacity of the fill fence was determined from the destructive fill fence test. The destructive fill fence test was a novel approach to determining the ultimate capacity of the fence. Although ultimate failure was not reached, Figure 10 shows that the fence began to yield at $100 \mathrm{kPa}$ or 10 tonnes of load per metre squared. It was determined that in the destructive fill fence test, the yielding material and the majority of the loads were distributed within the rebar skeleton. With a yielding value of $100 \mathrm{kPa}$ and a $\mathrm{Ka}$ value 0.56 , using Rankine Theory, the fence as constructed could withstand a paste fill height of $9.5 \mathrm{~m}$. This theoretical barricade height exceeds the practical limits of mining at Red Lake, thus the fences are designed within an acceptable factor of safety.

From the research the following recommendations were implemented at Red Lake Mine:

- Fill fence construction is suitable to the applied loads measured during the testing. No alterations to fence construction were made as miners are comfortable with construction.

- Maximum pressures were recorded during paste line flushes. In order to reduce loads on fence, line flushes should be done outside of the backfilled stopes.

- Continuous pouring can be carried to improve turn-around time on stopes and eliminate the ground fall hazard.

\section{Acknowledgements}

Financial support was provided by Goldcorp Ltd's Red Lake Mine and NSERC Industry Partnership Scholarship. The authors would like to acknowledge Rocscience for providing software and Yieldpoint for assistance with instrumentation. Thanks to the students who began, and contributed a significant amount of work on this project - Josh Clelland, Ali Rana and Kathryn Dehn. Thanks are due to the workforce at the Red Lake Mine for their assistance throughout. Specifically thanks to Grant Corey, Boi Linh Van, Danielle Pelletier and Ray Wilkins.

\section{References}

Dehn, K.K., Pakalnis, R. and Corey, G. (2007) Determining fill fence stability during increased backfill rates at an underground hard rock mine. Proceedings of MINEFILL 2007. Montreal, Quebec.

Golder Associates Ltd (2000) Paste backfill plant - operational manual. Report prepared for Goldcorp Ltd. Red Lake Mine. Report 991-9934.

Mah, P., Tessier, M. and Clelland, J. (2003) Mining methods at Goldcorp's Red Lake mine. Proceedings of the 2003, 16th CIM Mine Operators Conference. Oct 19-22, 2003. Saskatoon, Saskatchewan.

Marcinyshyn, K., Pakalnis, R., Dunbar, S. and Vongpasial, S. (1997) Sill mat design. Proceedings of the 1999, CIM Annual General Meeting. May 1999. Edmonton, Alberta.

Mitchell, R.J., Smith, J.D. and Libby, D.J. (1975) Bulkhead pressures due to cemented hydraulic backfills. Canadian Geotechnical Journal, 12.

Mott, R. (2002) Applied strength of materials. Ontario: Prentice Hall.

Revell, M.B. and Sainsbury, D.P. (2007) Paste bulkhead failures. Proceedings of MINEFILL 2007. Montreal, Quebec.

Terzaghi, K., Peck, R. and Mesri, G. (1996) Soil mechanics in Engineering Practice, Third Edition, John Wiley and Sons Inc.: New York.

Twomey, T. and McGibbon, S. (2001) The geological setting and estimation of gold grade of the high-grade zone, Red Lake Mine, Goldcorp. Exploration and Mining Geology, 10(1-2), pp. 19-34. 